\title{
Long-term bladder and bowel management after spinal cord injury: a 20-year longitudinal study
}

\author{
Gordana Savic $^{1} \cdot$ Hans L Frankel ${ }^{1} \cdot$ Mohamed Ali Jamous $^{1} \cdot$ Bakulesh M Soni $^{2} \cdot$ Susan Charlifue ${ }^{3}$
}

Received: 22 December 2017 / Revised: 31 January 2018 / Accepted: 1 February 2018 / Published online: 16 February 2018

(c) International Spinal Cord Society 2018

\begin{abstract}
Study design Prospective observational.

Aim The aim of this study was to analyse changes in bladder and bowel management methods in persons with long-standing spinal cord injury (SCI).

Setting Two spinal centres in UK.

Method Data were collected through interviews and examinations between 1990 and 2010 in a sample of persons injured more than 20 years prior to 1990.

Results For the 85 participants who completed the 2010 follow-up, the mean age was 67.7 years and the mean duration of injury was 46.3 years, $80 \%$ were male, $37.7 \%$ had tetraplegia AIS grade A, B, or C, $44.7 \%$ paraplegia AIS A, B, or C, and $17.6 \%$ an AIS D grade regardless of level. In all, 50.6\% reported having changed their bladder method, $63.1 \%$ their bowel method, and $40.5 \%$ both methods since they enroled in the study. The reasons for change were a combination of medical and practical. In men, condom drainage remained the most frequent bladder method, and in women, suprapubic catheter replaced straining/expressing as the most frequent method. The use of condom drainage and straining/expressing bladder methods decreased, whereas the use of suprapubic and intermittent catheters increased. Manual evacuation remained the most frequent bowel management method. The percentage of participants on spontaneous/voluntary bowel emptying, straining and medications alone decreased, whereas the use of colostomy and transanal irrigation increased over time.

Conclusions More than half the sample, all living with SCI for more than 40 years, required change in their bladder and bowel management methods, for either medical or practical reasons. Regular follow-ups ensure adequate change of method if/when needed.
\end{abstract}

\section{Introduction}

Complete or partial loss of voluntary bladder and bowel control after spinal cord injury (SCI) can have both medical and social consequences for the persons affected by them.

Preservation of renal function through renal surveillance is one of the most important tasks in long-term follow-up of

Gordana Savic

Gordana.Savic@buckshealthcare.nhs.uk or

gordanasavic@yahoo.com

1 National Spinal Injuries Centre, Stoke Mandeville Hospital, Buckinghamshire Healthcare NHS Trust, Aylesbury, UK

2 North West Regional Spinal Injuries Centre, Southport Hospital, Southport and Ormskirk NHS Trust, Southport, UK

3 Craig Hospital, Englewood, CO, USA people with SCI, and renal surveillance has become a standard part of long-term SCI care in many centres. During these follow-ups, bladder management method sometimes requires change, in order to ensure adequate bladder emptying and continence, but also to fit in with the person's lifestyle [1-3]. Sekar et al. reported that the method of bladder management itself might not impact renal function, as long as repeated vesicoureteric reflux is avoided [1].

Loss of bowel control, and particularly bowel incontinence, is often described by those experiencing it as the most socially disabling aspect of their SCI, which can have a marked impact on a person's quality of life [4]. People with SCI use different physical, pharmacological, and lifestyle techniques in order to achieve bowel continence and a successful bowel evacuation at a desired time. These may require modifications from time to time, or even a complete change, which is why bowel management issues form part of regular follow-ups after SCI [5-7]. 
Table 1 Percentage (\%) of participants on each bladder management method by study round (1990-2010)

\begin{tabular}{|c|c|c|c|c|c|c|c|}
\hline \multirow[t]{2}{*}{ Bladder management method } & \multicolumn{7}{|c|}{ Study round } \\
\hline & $\begin{array}{l}1990 \\
n=79\end{array}$ & $\begin{array}{l}1993 \\
n=84\end{array}$ & $\begin{array}{l}1996 \\
n=84\end{array}$ & $\begin{array}{l}1999 \\
n=85\end{array}$ & $\begin{array}{l}2002 \\
n=82\end{array}$ & $\begin{array}{l}2006 \\
n=81\end{array}$ & $\begin{array}{l}2010 \\
n=85 \\
\end{array}$ \\
\hline Voluntary control (\%) & 17.7 & 17.9 & 14.3 & 15.3 & 12.2 & 14.8 & 14.1 \\
\hline Straining/expressing $(\%)$ & 15.2 & 11.9 & 13.1 & 10.6 & 13.4 & 9.9 & 7.1 \\
\hline Condom drainage $(\%)$ & 49.4 & 51.2 & 51.2 & 48.2 & 35.4 & 37.0 & 29.4 \\
\hline Intermittent catheter $(\%)$ & 3.8 & 6.0 & 8.3 & 9.4 & 14.6 & 16.0 & 18.8 \\
\hline Indwelling urethral catheter $(\%)$ & 6.3 & 4.8 & 4.8 & 5.9 & 8.5 & 6.2 & 10.6 \\
\hline Suprapubic catheter $(\%)$ & 2.5 & 3.6 & 3.6 & 4.7 & 11.0 & 12.3 & 15.3 \\
\hline Conduit (\%) & 2.5 & 2.4 & 2.4 & 2.4 & 2.4 & 2.5 & 3.5 \\
\hline Sacral anterior root stimulator $(\%)$ & 2.5 & 2.4 & 2.4 & 3.5 & 2.4 & 1.2 & 1.2 \\
\hline$p$-Value ${ }^{\mathrm{a}}$ & & $<0.001$ & $<0.001$ & $<0.001$ & $<0.001$ & $<0.001$ & $<0.001$ \\
\hline$p$-Value ${ }^{\mathrm{b}}$ & & & $<0.001$ & $<0.001$ & $<0.001$ & $<0.001$ & $<0.001$ \\
\hline
\end{tabular}

${ }^{a}$ Chi-square test-comparison with methods proportion in 1990

${ }^{\mathrm{b}}$ Chi-square test—comparison with methods proportion in the previous round

The aim of this article was to analyse change in bladder and bowel management methods in a cohort of persons with long-standing SCI over a 20-year study period between 1990 and 2010.

\section{Methods}

The study took place at two British spinal centres: the National Spinal Injuries Centre (NSIC) at Stoke Mandeville Hospital, Buckinghamshire Healthcare NHS Trust and the North West Regional Spinal Injuries Centre (NWRSIC) at Southport Hospital, Southport and Ormskirk NHS Trust, and in collaboration with Craig Hospital, Englewood, CO, USA.

\section{Sample}

The sample included 85 participants of the British ageing with SCI study who were seen in at least five study rounds, including the baseline (1990 or 1993) and the final 2010 follow-up. The original study inclusion criteria were: traumatic SCI, injured prior to 1971, admitted to the participating spinal centres (Stoke Mandeville or Southport) within 1 year of injury, resident in the catchment area of the two participating centres, and aged between 15 and 55 at the time of injury.

The sample was identified through a thorough medical record review at the two spinal centres, with records dating back to 1944 at Stoke Mandeville and 1948 in Southport. Individuals meeting the study inclusion criteria were invited to participate in the study and come to one of the two centres for a full evaluation. A detailed explanation of the sample identification procedure can be found in the original ageing study manuscript [8].

\section{Data collection}

Subsequent to the original 1990 round, there were six follow-up assessments: in 1993, 1996, 1999, 2002, 2006, and 2010. Data were collected through retrospective medical records review, detailed medical and psychosocial interview, a full physical assessment, and diagnostic procedures. Participants who could not travel to one of the spinal centres but wanted to continue their participation in the study were seen either at home, or had a detailed medical and psychosocial interview by telephone only.

For analysis purposes, the sample was divided into three injury severity subgroups, based on the International Standards for Neurological Classification of Spinal Cord injury (ISNCSCI) [9]: individuals with tetraplegia and American Spinal Injuries Association (ASIA) Impairment Scale (AIS) grade $\mathrm{A}, \mathrm{B}$, or $\mathrm{C}$ (tetra $\mathrm{ABC}$ ), those with paraplegia and AIS grade $\mathrm{A}, \mathrm{B}$, or $\mathrm{C}$ (para $\mathrm{ABC}$ ), and those with very incomplete injuries regardless of the level (all AIS Ds). There were no ventilator-dependent participants in the study.

\section{Data analysis}

Descriptive statistics were used for describing demographic and injury characteristics of the sample and bladder and bowel method. Difference in means tests (paired sample $t$ test, $t$-test) and difference in frequencies of occurrence (chisquare test) were used for analysing changes in bladder and bowel method over time, and for differences between subgroups. Statistical significance level was set at $p<0.05$.

Data analyses were performed using the Statistical Package for the Social Sciences (SPSS), version 17 (SPSS Inc., Chicago, IL, USA). 


\section{Statement of ethics}

The original 1990 study and each study follow-up had a separate ethical approval, the last one by Oxfordshire Research of Ethics Committee B Committee, reference 10/ H0605/24.

We certify that all applicable institutional and governmental regulations concerning the ethical use of human volunteers were followed during the course of this research.

\section{Results}

\section{Sample characteristics}

Out of the total of 293 ageing study participants, 85 completed the 2010 follow-up and made up the sample for this

Table 2 Percentage (\%) of participants on each bladder management method by gender, for 1990 and 2010 study rounds

\begin{tabular}{llllll}
\hline Bladder management method & \multicolumn{2}{l}{ Males } & & \multicolumn{2}{l}{ Females } \\
\cline { 2 - 3 } \cline { 5 - 6 } \cline { 5 - 6 } & \multicolumn{2}{l}{ Study round } & & \\
\cline { 2 - 3 } & 1990 & 2010 & & 1990 & 2010 \\
& $n=62$ & $n=68$ & & $n=17$ & $n=17$ \\
\hline Voluntary control (\%) & 21.0 & 16.2 & & 5.9 & 5.9 \\
Straining/expressing (\%) & 6.5 & 2.9 & & 47.1 & 23.5 \\
Condom drainage (\%) & 62.9 & 36.8 & & 0 & 0 \\
Intermittent catheter (\%) & 1.6 & 19.1 & & 11.8 & 17.6 \\
Indwelling urethral catheter (\%) & 6.5 & 11.8 & & 5.9 & 5.9 \\
Suprapubic catheter (\%) & 1.6 & 10.3 & & 5.9 & 35.3 \\
Conduit (\%) & 0 & 1.5 & & 11.8 & 11.8 \\
Sacral anterior root stimulator (\%) & 0 & 1.5 & & 11.8 & 0 \\
$p$-Value $^{\mathrm{a}}$ & $p<0.001$ & & $p=0.248$ \\
\hline
\end{tabular}

${ }^{a}$ Chi-square test-comparison of methods proportion between 1990 and 2010 rounds article. Another 72 participants withdrew from the study or were lost to follow-up, and 136 were known to have died during the course of the study.

The mean age for the 85 participants in 2010 was 67.7 years (standard deviation (SD) 6, range 55-82), and the mean time since injury was 46.3 years (SD 4.6, range $40-59), 80 \%$ of the sample was male, $37.7 \%$ had tetraplegia and AIS grade A, B, or C lesion, $44.7 \%$ paraplegia and AIS $\mathrm{A}, \mathrm{B}$ or $\mathrm{C}$ lesion, and the remaining $17.6 \%$ were in the AIS grade D group. There were no ventilator-dependent participants in the sample.

\section{Bladder management method}

Looking at the entire 20 -year study period, $50.6 \%$ participants changed their bladder method sometime during the study. Table 1 presents the bladder management method in each study round between 1990 and 2010. Throughout the study, the most commonly used method was condom drainage, but its use decreased from $49.4 \%$ in 1990 to $29.4 \%$ in 2010 . The percentage of participants on voluntary control and straining/expressing methods also decreased. At the same time, the use of intermittent catheterisation and indwelling suprapubic catheters increased.

As bladder management methods differed between genders (no condom drainage equivalent for women), Table 2 shows bladder method by gender for the 1990 and 2010 study rounds. In men, the most frequently used method was condom drainage, but its use decreased from $62.9 \%$ in 1990 to $36.8 \%$ in 2010 . In women, straining/expressing (47.1\% in 1990) was replaced by suprapubic catheter $(35.3 \%$ in 2010$)$ as the most frequent method.

Table 3 presents the change of bladder management method from baseline. It shows that individuals on straining/expressing and condom drainage were the most likely to change their bladder management method over time.

Table 3 Bladder method change from baseline to 2010 follow-up, by baseline bladder management method

\begin{tabular}{|c|c|c|c|c|c|c|c|c|}
\hline \multirow[t]{2}{*}{ Baseline bladder method } & \multicolumn{8}{|c|}{2010 Bladder method } \\
\hline & Voluntary control & Straining/expressing & Condom & IC & IDUC & SP & Conduit & SARS \\
\hline Voluntary control, $n=14$ & $12(86 \%)$ & $0(0 \%)$ & $0(0 \%)$ & $1(7 \%)$ & $1(7 \%)$ & $0(0 \%)$ & $0(0 \%)$ & $0(0 \%)$ \\
\hline Straining/expressing, $n=12$ & $0(0 \%)$ & $6(50 \%)$ & $0(0 \%)$ & $3(25 \%)$ & $0(0 \%)$ & $3(25 \%)$ & $0(0 \%)$ & $0(0 \%)$ \\
\hline Condom, $n=45$ & $0(0 \%)$ & $0(0 \%)$ & $25(56 \%)$ & $10(22 \%)$ & $4(9 \%)$ & $5(11 \%)$ & $1(2 \%)$ & $0(0 \%)$ \\
\hline IC, $n=3$ & $0(0 \%)$ & $0(0 \%)$ & $0(0 \%)$ & $2(67 \%)$ & $0(0 \%)$ & $0(0 \%)$ & $0(0 \%)$ & $1(33 \%)$ \\
\hline IDUC, $n=5$ & $0(0 \%)$ & $0(0 \%)$ & $0(0 \%)$ & $0(0 \%)$ & $3(60 \%)$ & $2(40 \%)$ & $0(0 \%)$ & $0(0 \%)$ \\
\hline $\mathrm{SP}, n=2$ & $0(0 \%)$ & $0(0 \%)$ & $0(0 \%)$ & $0(0 \%)$ & $1(50 \%)$ & $1(50 \%)$ & $0(0 \%)$ & $0(0 \%)$ \\
\hline Conduit, $n=2$ & $0(0 \%)$ & $0(0 \%)$ & $0(0 \%)$ & $0(0 \%)$ & $0(0 \%)$ & $0(0 \%)$ & $2(100 \%)$ & $0(0 \%)$ \\
\hline SARS, $n=2$ & $0(0 \%)$ & $0(0 \%)$ & $0(0 \%)$ & $0(0 \%)$ & $0(0 \%)$ & $2(100 \%)$ & $0(0 \%)$ & $0(0 \%)$ \\
\hline
\end{tabular}

Numbers in bold represent the participants who remained on the same method

IC intermittent catheter, IDUC indwelling urethral catheter, SP suprapubic catheter, SARS sacral anterior root stimulator 
Table 4 Percentage (\%) of participants on each bowel management method by study round (1990-2010)

\begin{tabular}{|c|c|c|c|c|c|c|c|}
\hline \multirow[t]{2}{*}{ Bowel management method } & \multicolumn{7}{|c|}{ Study round } \\
\hline & $\begin{array}{l}1990 \\
n=79\end{array}$ & $\begin{array}{l}1993 \\
n=85\end{array}$ & $\begin{array}{l}1996 \\
n=84\end{array}$ & $\begin{array}{l}1999 \\
n=85\end{array}$ & $\begin{array}{l}2002 \\
n=82\end{array}$ & $\begin{array}{l}2006 \\
n=81\end{array}$ & $\begin{array}{l}2010 \\
n=85\end{array}$ \\
\hline No intervention (\%) & 21.5 & 16.7 & 17.9 & 14.1 & 13.4 & 19.0 & 16.7 \\
\hline Straining $(\%)$ & 10.1 & 3.6 & 4.8 & 10.6 & 12.2 & 2.5 & 8.3 \\
\hline Medication alone $(\%)$ & 16.5 & 15.5 & 9.5 & 10.6 & 9.8 & 10.1 & 13.1 \\
\hline Manual evacuation (\%) & 49.4 & 61.9 & 66.7 & 62.4 & 61.0 & 59.5 & 44.0 \\
\hline Colostomy (\%) & 2.5 & 2.4 & 2.4 & 2.4 & 3.7 & 8.9 & 14.3 \\
\hline Transanal irrigation (\%) & 0 & 0 & 0 & 0 & 0 & 0 & 3.6 \\
\hline$p$-Value ${ }^{\mathrm{a}}$ & & $<0.001$ & $<0.001$ & $<0.001$ & $<0.001$ & $<0.001$ & $<0.001$ \\
\hline$p$-Value ${ }^{\mathrm{b}}$ & & & $<0.001$ & $<0.001$ & $<0.001$ & $<0.001$ & $<0.001$ \\
\hline
\end{tabular}

${ }^{\text {a }}$ Chi-square test - comparison with methods proportion in 1990

${ }^{\mathrm{b}}$ Chi-square test-comparison with methods proportion in the previous round

Table 5 Bowel method change from baseline to 2010 follow-up, by baseline bowel management method

\begin{tabular}{lllllll}
\hline Baseline bowel method & \multicolumn{2}{l}{2010 Bowel method } & & \\
\cline { 2 - 6 } & No intervention & Straining & Medication alone & Manual evacuation & Colostomy & Transanal irrigation \\
\hline No intervention, $n=16$ & $\mathbf{1 2}(\mathbf{7 5 \%})$ & $1(6 \%)$ & $1(6 \%)$ & $1(6 \%)$ & $0(0 \%)$ & $1(6 \%)$ \\
Straining, $n=7$ & $0(0 \%)$ & $\mathbf{4}(\mathbf{5 7 \%})$ & $0(0 \%)$ & $2(29 \%)$ & $1(14 \%)$ & $0(0 \%)$ \\
Medication alone, $n=16$ & $0(0 \%)$ & $0(0 \%)$ & $\mathbf{4}(\mathbf{2 5 \%})$ & $9(56 \%)$ & $2(13 \%)$ & $1(6 \%)$ \\
Manual evacuation, $n=44$ & $0(0 \%)$ & $2(5 \%)$ & $4(9 \%)$ & $\mathbf{3 0}(\mathbf{6 8 \%})$ & $7(16 \%)$ & $1(2 \%)$ \\
Colostomy, $n=2$ & $0(0 \%)$ & $0(0 \%)$ & $0(0 \%)$ & $0(0 \%)$ & $\mathbf{2 ( 1 0 0 \% )}$ & $0(0 \%)$ \\
Transanal irrigation, $n=0$ & $0(0 \%)$ & $0(0 \%)$ & $0(0 \%)$ & $0(0 \%)$ & $0(0 \%)$ & $0(0 \%)$ \\
\hline
\end{tabular}

Numbers in bold represent the participants who remained on the same method

The most frequently stated reasons for changing the bladder method were: urine retention $(34.3 \%)$, urinary incontinence (20\%), unspecified medical advice (17.1\%), and frequent urinary tract infections $(8.6 \%)$. Another $11.4 \%$ stated practicality and personal preference, such as difficulties with toilet transfers, positioning (for intermittent catheterisation), dexterity (for intermittent catheterisation and condom application), and availability/accessibility of suitable toilets. The remaining $10 \%$ were cases of urethral damage/fistulae, urinary stones, catheter blockages, and allergy.

Time since injury differed significantly between participants who had changed their method and those who had not (47.7 vs 44.8 years, $t$-test $p=0.003$ ), but not their age (68.1 vs 67.2 years, $t$-test $=0.472$ ). Proportionally more participants with functionally complete tetraplegia $(59.4 \%$ of all tetra $\mathrm{ABCs}$ ) and functionally complete paraplegia $(50 \%$ of all para $\mathrm{ABCs}$ ) changed their bladder method during the study, compared with those with functionally incomplete lesions (33.3\% of all Ds), but the difference was not statistically significant (chi-square test, $p=0.249$ ). There was no statistically significant difference by gender; $50 \%$ of men and $52.9 \%$ of women changed their bladder method during the study (chi-square test, $p=0.828$ ).

\section{Bowel management method}

Between the 1990 and 2010 study rounds, $63.1 \%$ of participants changed their bowel management method. Table 4 presents the bowel management method in each study round between 1990 and 2010. Manual evacuation was the most common method throughout the study (49.4\% in 1990 and $44 \%$ in 2010). The percentage of individuals using spontaneous/voluntary emptying, straining, and medication alone decreased, whereas the use of colostomy increased during the study period. Table 5 gives the change of management method from baseline, and shows that participants on straining and medication alone were the most likely to change their bowel management method.

The reported reasons for bowel method change could be divided into gastrointestinal (44.5\%), other medical reasons (33.2\%), and personal choice $(22.3 \%)$. Gastrointestinal reasons included constipation (17.8\% of all named reasons), bowel irregularity and sluggishness (15.6\%), discomfort and bloating (6.7\%), and frequent bowel accidents (4.4\%). Named medical reasons $(24.4 \%)$ were bowel cancer, anal abscess, prolapsed rectum, haemorrhoids, change of medication, acute illnesses and accidents which required change 
of bowel routine. Another $8.8 \%$ reported unspecified recommendations by healthcare professionals. Reasons for change by personal choice $(22.3 \%)$ included lifestyle and diet changes, difficulty with toilet transfers, amount of time and effort required to complete the bowel programme, and need for additional help.

In 2010, the mean duration of the bowel programme was $35 \pm 33 \mathrm{~min}$ (range $1-120 \mathrm{~min}$ ). For $40 \%$ of the sample, it was $30 \mathrm{~min}$ or longer, and for $15 \% 60 \mathrm{~min}$ or longer. The majority, $79.2 \%$ emptied their bowels on the toilet, $15.3 \%$ on the bed, and the rest on the commode or over the toilet using a shower chair.

There was no statistically significant difference in age, time since injury, or age at injury between those who changed their bowel method and those who did not (67.8 vs 67.3 years, 46.7 vs 45.4 years, and 21.2 vs 21.9 years, respectively, $t$-test, all $p>0.05$ ), nor in the proportion of those who changed their bowel method when analysed by gender $(64.2 \%$ of men vs $58.8 \%$ of women, chi-square test, $p>0.05)$. Proportionally more participants with functionally complete tetraplegia ( $68.8 \%$ of all tetra $\mathrm{ABCs}$ ) and functionally complete paraplegia $(64.9 \%$ of all para $\mathrm{ABCs})$ changed their bowel method during the study, compared with those with incomplete lesions (46.7\% of all Ds), but the difference was not statistically significant (chi-square test, $p=0.328$ ).

Change of both bladder and bowel method during the 20year study period was reported by $40.5 \%$ of the sample.

\section{Discussion}

The aim of this article was to present changes in bladder and bowel management methods during the 20-year (1990-2010) longitudinal study on ageing with SCI in the remaining 85 participants, who were seen in at least five study rounds, including the baseline and the final 2010 follow-up. All participants had been injured for more than 40 years in 2010. Although the reasons for changing bladder and bowel methods were a combination of medical advice and personal preference, it is worth noting that certain management methods only became routinely available just before or during the study.

A publication from the earlier rounds of the same study reported that $28.8 \%$ of the original participants had changed their bladder method during the then 6-year study period, particularly those using straining or condom drainage [2]. It further reported that the probability of change increased with age and time since injury, but there was no specific association between reasons for change and bladder management method. The current study confirmed the conclusion that at a late stage post-injury there remained a high probability of change in bladder management method. More than half of our participants changed their bladder-emptying method during the 20-year study period, some more than once, and longer injury duration was associated with an increased probability of changing the method. The current study also found a decrease in straining/expressing and condom drainage methods and an increase in suprapubic and intermittent catheter usage. Although some of the changes may be explained by current standards of practice, generally they were implemented in order to accommodate an individual's changing needs. Recent studies from other centres reported intermittent catheterisation to be the most frequently used bladder method [10-14]. In later study rounds of our study, intermittent catheterisation ranked second in men, after condom drainage, and third in women, after suprapubic catheter and straining/expressing. A somewhat higher proportion of more conservative bladder methods in our sample may be due to the fact that some of the methods were not available in their early days postinjury. For instance, intermittent catheterisation and suprapubic catheter, the second and the third most frequent methods in 2010, were only introduced as standard methods of long-term bladder management in the 1980s.

Looking at bowel management, $63 \%$ of the sample reported having changed their method during the 20-year study duration. Manual evacuation remained the most common method throughout the study. However, only $70 \%$ of those using manual evacuation at baseline were still on the same method in 2010; the majority of those who changed their method went on to colostomy and few to other methods. Colostomy was the method that showed the greatest increase, from $2.6 \%$ in 1990 to $14.3 \%$ in 2010 . A recent British publication found high satisfaction with colostomies in individuals who had previously experienced significant neurogenic bowel management problems [15]. For the first time in 2010, there were three participants using transanal irrigation for bowel evacuation, which was introduced as a method in carefully selected individuals after a successful clinical trial $[16,17]$. Age and time since injury did not seem to affect bowel method change as much as bladder method change. Severity of SCI affected both, but did not reach statistical significance, possibly due to relatively small numbers in the sample subgroups. It is worth noting that for bowel management, people often used additional measures, such as diet, natural products, lifestyle changes etc., which were not included under bowel management methods. In contrast to our findings, a recently published Danish study did not find a significant change in methods of bowel care between 1996 and 2015 in their sample, but did report $20 \%$ of their participants undergoing surgery for bowel dysfunction, including $10 \%$ who had some form of stoma [18].

Finally, $40 \%$ of our participants changed both bladder and bowel management methods during the study. Bladder 
and bowel functions are closely related and often go together, so that treatment of one often impacts the other, and change in one method can have implications on the other [19]. Thus, these issues are typically addressed together in specialised spinal centres. For the best result, both bladder and bowel function should be discussed, assessed, and adjusted as needed during regular follow-ups, which form part of the lifelong care after SCI $[5,10,12,14,20]$.

\section{Study limitations}

Bladder and bowel-related medical complications were not addressed in this article due to missing data, as a number of ageing participants only had telephone interviews in the later study rounds, without full diagnostic assessment.

Relatively small numbers in the final follow-up, particularly when analysed by subgroups, may have affected the statistical significance results.

\section{Conclusions}

More than half the study participants, all injured for more than 40 years, changed their bladder or bowel management method, and 40\% changed both methods, during the 20-year study duration. In men, condom drainage remained the most frequent bladder method, but decreased over time. In women, suprapubic catheter replaced straining/expressing as the most frequent bladder method. Manual evacuation remained the most frequent bowel management method, but the use of colostomy and transanal irrigation increased in later study rounds. Reasons for method change were a combination of medical and practical ones. Addressing bladder and bowel function during regular SCI follow-ups ensures appropriate change of method when needed.

\section{Data archiving}

There were no data to deposit.

Acknowledgements We authors thank all the participants for taking part in the study, and staff at the collaborating spinal centres at Stoke Mandeville and Southport Hospitals, UK. Over the years, the study was financially supported by the following funders: 1990 and 1996National Institute on Disability and Rehabilitation Research (NIDRR), USA; 1993-Centers for Disease Control and Prevention (CDC), USA; 1999 and 2002-Ontario Neurotrauma Foundation, Canada; 2006-Buckinghamshire Hospitals NHS Trust Charitable Spinal Fund, UK; David Tolkien Trust Fund, UK; Southport and Ormskirk Hospital Spinal Injuries Centre Endowment Fund, UK; 2010-Buckinghamshire Healthcare NHS Trust Charitable Spinal Fund, UK and Ann Masson Legacy for Spinal Research Fund, UK.

\section{Compliance with ethical standards}

Conflict of interest The authors declare that they have no conflict of interest.

\section{References}

1. Sekar P, Wallace DD, Waites KB, DeVivo MJ, Lloyd LK, Stover $\mathrm{SL}$, et al. Comparison of long-term renal function after spinal cord injury using different urinary management methods. Arch Phys Med Rehabil. 1997;78:992-7.

2. Drake MJ, Cortina-Borja M, Savic G, Charlifue SW, Gardner BP. Prospective evaluation of urological effects of aging in chronic spinal cord injury by method of bladder management. Neurourol Urodyn. 2005;24:111-6.

3. Savic G, Charlifue S, Glass C, Soni BM, Gerhart KA, Jamous MA. British ageing with SCI study: changes in physical and psychosocial outcomes over time. Top Spinal Cord Inj Rehabil. 2010;15:41-53.

4. Liu CW, Huang CC, Yang YH, Chen SC, Weng MC, Huang MH. Relationship between neurogenic bowel dysfunction and healthrelated quality of life in persons with spinal cord injury. J Rehabil Med. 2009;41:35-40.

5. Menter R, Weitzenkamp D, Cooper D, Bingley J, Charlifue S, Whiteneck G. Bowel management outcomes in individuals with long-term spinal cord injuries. Spinal Cord. 1997;35:608-12.

6. Faaborg PM, Christensen P, Finnerup N, Laurberg S, Krogh K. The pattern of colorectal dysfunction changes with time since spinal cord injury. Spinal Cord. 2008;46:234-8.

7. Coggrave M, Norton C, Wilson-Barnett J. Management of neurogenic bowel dysfunction in the community after spinal cord injury: a postal survey in the United Kingdom. Spinal Cord. 2009;47:323-30. quiz 331-3

8. Whiteneck G, Charlifue S, Frankel H, Fraser M, Gardner B, Gerhart K, et al. Mortality, morbidity and psychosocial outcomes of persons spinal cord injured more than 20 years ago. Paraplegia . 1992:30:617-30.

9. American Spinal Injury Association. International Standards for Neurological Classification of Spinal Cord Injury. Atlanta, GA: American Spinal Injury Association; 2015 (revised 2011).

10. Hansen RB, Biering-SorensenF, Kristensen JK. Bladder emptying over a period of 10-45 years after a traumatic spinal cord injury. Spinal Cord. 2004;42:631-7.

11. Rabadi MH, Aston C. Complications and urologic risks of neurogenic bladder in veterans with traumatic spinal cord injury. Spinal Cord. 2015;53:200-3.

12. Adriaansen JJ, van Asbeck FW, Tepper M, Faber WX, Visser-Meily JM, de Kort LM, et al. Bladder-emptying methods, neurogenic lower urinary tract dysfunction and impact on quality of life in people with long-term spinal cord injury. J Spinal Cord Med. 2017;40:43-53.

13. Krebs J, Wöllner J, Pannek J. Risk factors for symptomatic urinary tract infections in individuals with chronic neurogenic lower urinary tract dysfunction. Spinal Cord. 2016;54:682-6.

14. El-Masri WS, Chong T, Kyriakider AE, Wang D. Long-term follow-up study of outcomes of bladder management in spinal cord injury patients under the care of the Midlands Centre for Spinal Injuries in Oswestry. Spinal Cord. 2012;50:14-21.

15. Coggrave MJ, Ingram RM, Gardner BP, Norton CS. The impact of stoma for bowel management after spinal cord injury. Spinal Cord. 2012;50:848-52. 
16. Christensen P, Bazzocchi G, Coggrave M, Abel R, Hultling C, Krogh $\mathrm{K}$, et al. A randomized, controlled trial of transanal irrigation versus conservative bowel management in spinal cord-injured patients. Gastroenterology. 2006;131:738-47.

17. Christensen P, Bazzocchi G, Coggrave M, Abel R, Hulting C, Krogh K, et al. Outcome of transanal irrigation for bowel dysfunction in patients with spinal cord injury. J Spinal Cord Med. 2008;31:560-7.
18. Nielsen SD, Faaborg PM, Finnerup NB, Christensen P, Krogh K. Ageing with neurogenic bowel dysfunction. Spinal Cord. 2017;55:769-73.

19. Cameron AP, Rodriguez GM, Gursky A, He C, Clemens JQ, Stoffel JT. The severity of bowel dysfunction in patients with neurogenic bladder. J Urol. 2015;194:1336-41.

20. Martinez L, Neshatian L, Khavari R. Neurogenic bowel dysfunction in patients with neurogenic bladder. Curr Bladder Dysfunct Rep. 2016;11:334-40. 